\title{
El 11-S, o modernidad y terror
}

\author{
Agnes Heller \\ New School for Social Research \\ Nueva York
}

\section{Resumen}

La autora centra su argumentación alrededor de la genealogía del terror hasta dar con la acción con apego al terror como un tipo de acción no exclusiva de organizaciones o estados totalitarios como los representados por las «modernidades» nacionalsocialista y comunista, sino como un tipo de acción también susceptible de ser vehiculizada por agentes violentos no estatales. Éstos, dice contundentmente, han transmutado rasgos de los grupos activos y extremistas de los años setenta que enfrentaron al poder contenido en sus respectivos estados nacionales, bajo un nuevo programa ideológico. Sin embargo, el terrorista del tipo de Bin Laden y sus seguidores, a juicio de Heller, son parte de narrativas pantópicas y totalitarias, fundadas en la no-libertad y que discurren sobre la reunificación de mundos musulmanes. Su supuesta misión recurre a y moviliza sus recursos disponibles, "el miedo, la intimidación sin precedentes» y "la muerte indiscriminada»: "los dos significados de la palabra terron.

Palabras clave: globalización, terror, modernidad, fundamentalismo, jacobinismo.

\section{Abstract. 9-11-2001, or Modernity and Terror}

The author takes into account the sociological meaning of the New Terror that rises from the 9-11-2001 as an ever recurring dark side of modernity, the sectarian, totalitarian and jacobin tendencies which are built in the political program of modernity from the very beginning in the French Revolution, and continued in the german nazi Endelösung and in the Russian and Chinese Revolutions. The New Terror reshapes the two key meanings of Terror: fear and unprecedented intimidation, on the one hand, and indiscriminate death.

Key words: globalization, terror, modernity, fundamentalism, Jacobinism.

Hace un año, decidí dar la espalda a la teoría política y escribir sobre política tan sólo como ciudadana. En un arranque de optimismo, me felicité asumiendo que, en las esferas de la filosofía y la teoría social, ya había cumplido con mi deber y, por lo tanto, merecía dedicarme finalmente, y de manera exclusiva, a tópicos más gratificantes, como por ejemplo el arte o la religión. El 11 de septiembre me demostró que estaba equivocada. No porque hubiera compartido ni por un minuto la creencia general, popular a principios de la década de 1990, que los tiempos de totalitarismo y terror habían acabado, porque nunca 
he dejado de enfatizar lo contrario. Seguían con nosotros, siempre al margen, y siempre cabía la posibilidad de que, tarde o temprano, amenazaran al orden político de la democracia liberal de otra manera. A pesar de todo, creía o, mejor dicho, esperaba que esto sucedería más tarde que temprano; que podríamos disfrutar de unas cuantas décadas de tregua. A estas alturas, es de conocimiento general que los acontecimientos políticos son contingentes, que no se pueden prever ni predecir y, sin embargo, que después de que aparezcan se pueden llegar a entender, sólo de forma aproximada, las condiciones estructurales (es decir, estructuras tanto políticas como mentales) de su aparición. Tras el ataque del 11 de septiembre, se hizo evidente que una oleada de terror amenaza otra vez a las democracias liberales. No sabemos dónde ni cómo volverá a golpear, porque todos los acontecimientos son contingentes y no se pueden prever, pero ya sabemos muchas cosas con respecto a la organización, la operación, los portadores sociales y la ideología del terror global; sabemos lo suficiente para llegar a una comprensión aproximada.

El discurso de la comprensión ya está en marcha y este estudio quiere ser una contribución a él. Sin embargo, no lo habría escrito si no hubiera sido expuesta en varias afirmaciones bastante sofisticadas de literatos que me irritaron hasta el punto que me vi empujada a hacer pública mi opinión. No tengo por qué dar nombres, estadounidenses o alemanes, todos intelectuales de renombre, los escritos de los cuales me sorprendieron, no solamente por su carencia de sensibilidad, sino también por su inoportunidad. Ellos han marcado el tono, o al menos un tono que se ha sentido por encima de muchos otros. Confrontaré aquí, no sólo sus afirmaciones, sino también otras opiniones que ahora son típicas. Por descontado, entro a discutir sólo con aquéllos que son compañeros de debate. La condición mínima para participar es la condena del acto terrorista del 11-S como «inhumano» o «inexcusable». Aquéllos que lo condenan, aunque con reservas, no son participantes, ni reales ni potenciales, de este discurso.

Permitidme enumerar los grupos de los actuales argumentos.

1. Primero, hay los denominados argumentos de la «globalización»:

a) La distribución escandalosamente desigual de los bienes, la creciente brecha entre ricos y pobres, y la pobreza mundial en general desesperan e irri$\tan$ a la gente.

El terror es una respuesta, como lo son las manifestaciones de Seattle o Génova.

Es, naturalmente, una respuesta equivocada. Sin embargo, es una respuesta.

En la medida que es una respuesta a los males de la globalización, podemos frustrar el terrorismo poniendo fin a la globalización, limitando y finalmente rompiendo el poder del comercio internacional y restaurando las economías y los mercados locales.

b) El terror es una respuesta al capitalismo en general; es una afirmación anticapitalista (aunque equivocada). El capitalismo destruye las formas tradi- 
cionales de vida, religión y moralidad. Es hedonista y decadente. Despliega la tecnología que envenena el medio ambiente. En respuesta a esta visión, la idea es que se podría poner fin al terror con la introducción de tecnologías alternativas, y parar así la propagación de la denominada «decadencia occidental».

2. Segundo, hay el argumento de «la América culpable»:

a) Los Estados Unidos siempre han sido culpables, especialmente con respecto a sus relaciones con el mundo árabe y musulmán, el cual ha sido siempre humillado y frustrado por América del Norte. Una intervención secreta de los Estados Unidos llevó al trono al sha del Irán; los Estados Unidos defendieron a los dictadores militares de Pakistán; apoyaron a los fundamentalistas (Bin Laden incluido) de Afganistán en contra de los soviéticos; hicieron la guerra contra Irak; siguen ayudando a los regímenes reaccionarios del mundo árabe, por ejemplo Arabia Saudí, y apoyan a Israel en contra de los palestinos.

b) Los Estados Unidos son la fuente de la abominación moral: toleran la homosexualidad, la amoralidad de las mujeres, la vestimenta frívola, las drogas y el alcoholismo — cosas que se extienden por el mundo con la ayuda de la hegemonía de la cultura de masas americana.

c) Este puñado de argumentos normalmente incluyen la predicción de que los Estados Unidos se vengarán (como siempre) del ataque terrorista. Como en Yugoslavia, habrá muchas víctimas civiles. Los Estados Unidos causarán más daño del que han sufrido (como siempre), quizás, incluso, una tercera guerra mundial. El quid de la cuestión es que los Estados Unidos harán cualquier cosa por preservar su dominación del mundo, cueste lo que cueste.

3. Tercero, hay el argumento "fundamentalista islámico»:

a) Es equivocado creer que el islam está representado en la Biblia. Los musulmanes ni conocen la Biblia. El fanatismo y el fundamentalismo son la esencia del islam. El islam no permite la ilustración; se resiste a la modernidad.

b) La principal guerra de la modernidad es una guerra cultural. Las culturas europea y musulmana no pueden coexistir. El islam es inferior a la cultura europea, pero reclama su superioridad. La exaltación resentida y el odio del islam en contra de un absoluto aunque más próspero extraño alimenta a los ataques terroristas.

Antes de tratar estos argumentos uno por uno, quiero señalar algo que todos tienen en común. Todo estudiante de sociología de primer año aprende la diferencia entre explicación y comprensión, y repetirá la lección bien aprendida de que no hay fenómeno social e histórico o acontecimiento que se pueda entender por la vía de la explicación, sino tan sólo por la comprensión («Verstehen!» repetirá con orgullo durante el examen). Ninguno de los argumentos antes mencionados explican los ataques terroristas contra el WTC y 
el Pentágono tan sólo con la enumeración de las causas. Hacerlo es, naturalmente, un disparate filosófico que Aristóteles ya repudiaba en su Metafisica. Incluso si se pudieran enumerar las causas suficientes de un acontecimiento histórico, cosa que es imposible, el acontecimiento seguiría siendo contingente y totalmente incomprendido. Aristóteles dijo que se tiene que saber la causa final y la causa formal, es decir, la esencia o la función de algo, con objeto de explicarlo o entenderlo. Volveré pronto a esta cuestión, pero, primero, dejadme examinar las «causas» antes mencionadas.

Con respecto al primer grupo de argumentos, es cierto que el mundo está ahora dividido entre países ricos y pobres, y que en los últimos diez años el abismo se ha ensanchado. Añadiría que la brecha también se ha ensanchado dentro de los países, por ejemplo en los Estados Unidos. Dudo, no obstante, que la globalización sea la responsable de todos los males. El abismo entre países ricos y pobres es en efecto un problema global, y por eso es por lo que se tiene que tratar de una manera global y no antiglobal. Es obvio que sólo un tipo de política socialdemócrata de la redistribución puede abordar el tema con un mínimo de esperanza de éxito. Sin embargo, la socialdemocracia es el enemigo número dos del terrorismo mundial, como lo es toda formación liberal, secular, social o política. Además, no son los pobres sino los muy ricos quienes dirigen el terrorismo global, y quienes lo ejecutan son, incluso, los hijos de clases medias, principalmente de clase media-alta. Están muy lejos de ser los desheredados de la Tierra.

Los participantes en las protestas masivas en contra de la globalización son muy diversos ideológicamente. Aunque determinadas organizaciones terroristas aprovechen la ocasión de estas manifestaciones para ejercer la violencia, no representan todo el movimiento. Bien al contrario, el terror global es hijo de la globalización. El terror organizado globalmente es el terror de un mundo global.

Que el capitalismo destruye muchas formas de vida anteriores es cierto. Por ejemplo, destruye las monarquías tradicionales, las aristocracias tradicionales, los estados inamovibles y rígidamente divididos, y la autosuficiencia rural. Aún así, si echamos una ojeada atenta a los líderes o miembros de las organizaciones terroristas, nos daremos cuenta enseguida de que son beneficiarios del capitalismo: adeudan su posición a la destrucción de las estructuras tradicionales. El padre de Bin Laden no era príncipe ni hijo de príncipe, sino un hombre hecho a sí mismo, un nuevo burgués, como lo era el padre de Atta. El enemigo número tres del terrorismo global es precisamente la (casi) última monarquía tradicional del mundo árabe, mientras que sus mejores amigos son sus dictadores revolucionarios, como por ejemplo Siria, Irak y Libia. Ayer eran leninistas, es decir, fundamentalistas seculares (algunos aún lo son); ahora se han vuelto fundamentalistas musulmanes. Desde nuestra perspectiva presente, esto equivale a lo mismo. Sólo hay fundamentalismo donde no hay fundamentos.

Vamos ahora al segundo argumento, el de la «América culpable». Los Estados Unidos han cometido muchos errores en política exterior, y han tomado muchas decisiones erróneas. También han tomado muchas decisiones dignas de elo- 
gio y buenas. En los últimos diez años, desde la caída de la Unión Soviética, a mi parecer, las buenas decisiones pesan más que las malas. Pero incluso si se cree lo contrario, el hecho sigue siendo que el ataque terrorista no tiene nada que ver con las acciones anteriores de los Estados Unidos, buenas o malas. Las dos cosas no están para nada relacionadas. El proceso de paz palestino-israelí ya estaba en marcha (con la ayuda de los EEUU) cuando el ataque terrorista en los Estados Unidos estaba en una fase de preparación adelantada. Los esfuerzos de los grupos terroristas en esta fase no harían más que parar el proceso de paz y, por lo tanto, no ayudarían a los palestinos. No me sorprendería si resultara que la organización que hay detrás de la segunda Intifada es corresponsable del ataque contra objetivos de los Estados Unidos.

La imagen de la «América culpable» es una imagen ideológica. No es la causa de nada, pero sirve como justificación para todo. Una vez, cuando un americano expresó su horror hacia los juicios farsa de Moscú, le respondieron que en los Estados Unidos pegan a los negros. Esto último era verdad, pero no tenía nada que ver con los juicios farsa soviéticos ni con los campos de concentración; estaba destinado a servir como justificación ideológica para todo. Como entonces, lo mismo pasa hoy con el argumento de la "América culpable». Sus defensores dicen: «el ataque estuvo mal, desde luego, pero, aún así, tienen parte de razón» - lo cual quiere decir que hay cierta justificación. Aún hemos de aprender la verdad filosófica más sencilla: no se puede decir una mentira en diez frases sin decir alguna verdad. Las ideologías hacen uso de esta realidad común. Siempre convierten una pequeña verdad en una gran mentira. Naturalmente que es cierto que el Tratado de Versailles fue injusto, pero justificar con esto a Hitler fue una pérfida mentira.

Si el mundo árabe se siente frustrado, no son los Estados Unidos quienes han causado la frustración. La frustración, que es real, es el resultado del fracaso del intento de crear un estado panárabe y de la derrota del nacionalismo panárabe. La ideología leninista, que fue adoptada ampliamente en el tiempo de Nasser, y la toma del poder por parte del partido Ba'ath, ayudaron poco a la perspectiva de construcción del imperio. Ésta es la prehistoria, si bien no la causa, del surgimiento y la demostración de fuerza del fundamentalismo islámico, que, de hecho, se originó en un país no árabe, el cual ya está reñido con el mundo árabe contemporáneo.

A la predicción: «Los Estados Unidos reaccionarán de forma exagerada y volverán a tirar bombas sobre la población civil», responderé sólo brevemente. En mi opinión, los ataques contra Irak y Yugoslavia estuvieron justificados. Pero incluso aquéllos que piensan lo contrario tienen que admitir que en todas las tradiciones de teoría de la guerra justa, desde Grotius hasta hoy, el ataque del 11-S en los Estados Unidos es uno de los casos más puros e incontestables de ius ad bellum, el derecho a la guerra. Cualquier comparación con Pearl Harbour es poco sólida, porque los japoneses atacaron a la marina y a la fuerza aérea, beligerantes potenciales, mientras que el ataque del 11-S golpeó inmediatamente no beligerantes reales y potenciales. El ataque también violó (sin estado de guerra) la ius in bello, es decir, el principio de conducta justa en la 
guerra. La cuestión sobre cómo debería ser la represalia de los Estados Unidos es pragmática, una cuestión de juicio, no una cuestión de justicia o derecho. (Como explicación sólo diré que tener el derecho de hacer la guerra no equivale a "ser bueno» — primero porque sólo los individuos pueden ser buenos, no los estados; y segundo porque, incluso con respecto a los individuos, nadie es bueno porque haga algo en defensa propia. Todo lo contrario, se es bueno si se ayuda a las víctimas de la agresión sin ser atacado. Sin embargo, esta condición no afecta a los estados soberanos.)

Ahora me quiero referir al último grupo de explicaciones: «Fundamentalismo musulmán». Es cierto que la gente del islam no es la gente de la Biblia (no la aprenden; no es su libro sagrado), y que en esto se diferencian de las otras dos religiones monoteistas tradicionales, pero creo que esto tiene muy poco que ver con nuestra cuestión. Los primeros terroristas suicidas eran japoneses, no musulmanes. Hay una tradición musulmana de fanatismo, pero también la hay en las tradiciones judía y cristiana. Por lo que se refiere a la superioridad de la tradición europea respecto al islam, hay que tener una memoria muy corta para creérselo. Los dos regímenes totalitarios de terror del siglo XX, nazismo y bolchevismo, fueron los inadaptados de la cultura europea. Del mismo modo que no se puede entender a la Unión Soviética a partir de los textos de Marx o el nazismo a partir de los textos de Gobineau o de Nietzche, también es absurdo intentar entender a Bin Laden a partir del Corán. En efecto, el Corán aprueba la jihad, Karl Marx impulsó la dictadura del proletariado y Nietzche alabó la bestia rubia. ¿Y qué? Los regímenes del terror necesitan textos tradicionales por razones ideológicas; los usan y hacen un mal uso de ellos como ideologías. Ningún texto tendría que ser leído desde la perspectiva de su implementación ideológica.

Querría añadir una observación personal a todo esto. A pesar de que hablamos de fundamentalismo musulmán como ideología de la nueva oleada de terrorismo postmoderno y global, y con razón, por el momento todos los miembros de organizaciones terroristas, incluyendo los führers, son musulmanes árabes. El avivamiento musulmán empezó en Irak, pero no veo ningún iraquí entre los terroristas. Ni veo ningún pakistaní, ni malasio, ni turco o indonesio, ni siquiera un afgano. En casi todas estas sociedades musulmanas hay manifestaciones antiamericanas, griterío y multitudes que traen pósters con imágenes de su führer, Bin Laden. Pero todos los organizadores principales (por lo que sabemos), todos los terroristas suicidas, e incluso los terroristas sospechosos arrestados son árabes. ¿Quizás se necesita el cruce entre la ideología de una cultura guerrera y el islam como ideología para producir la nueva oleada de terrorismo?

El fundamentalismo es un fenómeno moderno. Es una reacción al proceso de la ilustración, a la destrucción/construcción de los órdenes sociales tradicionales, a la idea de progreso, de la creencia en el racionalismo, de la pérdida de las comunidades naturales, de las identidades, de la seguridad y de la certeza - una reacción a la contingencia y a las cargas de una libertad abstracta que el individuo puede usar sean cuales sean las consecuencias. 
El fundamentalismo es un sistema cerrado de creencias, seculares o religiosas, y no admite ninguna discusión sobre su compatibilidad o incompatibilidad con cualquier otro sistema de creencias, porque es considerado por definición incompatible. El fundamentalismo ofrece fundamentos en un mundo donde no los hay. Funciona con el tradicional concepto religioso monoteísta de la verdad (cualquier otra cosa es herejía o paganismo, perverso, malo, etc.). El deseo de pertenecer, la intranquilidad de ser una minoría, el impulso de deshacerse de la carga del pensamiento independiente — todo contribuye a una tendencia hacia el fundamentalismo, y está presente en cualquier parte del mundo moderno, incluso entre los liberales. El fundamentalismo también pertenece a la historia (pasada y presente) de los Estados Unidos.

Un sistema cerrado de creencias (seculares o religiosas) es una condición previa del terrorismo internacional, pero tan sólo una de muchas. La segunda condición es una organización totalitaria. La organización totalitaria la inventó Lenin en 1903, en el congreso fundacional de la facción bolchevique del Partido Social Demócrata Ruso. Lenin inventó una organización de partido que tenía que funcionar como un ejército. El centro da las órdenes y, cada unidad, en los niveles jerárquicamente estructurados de la organización, obedece. Un partido así, indicó Lenin, puede operar de forma segura clandestina e ilegalmente. La organización es una totalidad, porque se basa en una verdad y en un objetivo común. En opinión de Lenin, cada miembro tendría que aceptar la doctrina marxista como la Verdad, compartir el objetivo de tomar el poder, la dictadura del proletariado, la revolución mundial y la destrucción del capitalismo. Añadió dos características más al cuadro. La democracia y el liberalismo son enemigos, entre otras razones porque los liberales sólo hablan, mientras que los revolucionarios hemos de actuar y, además, porque los intelectuales son aquéllos a quienes les gusta discutir, mientras que los trabajadores prefieren la acción. En el cuadro de Lenin, todo el mundo que está en una posición de mando dentro del partido es por definición un trabajador, es decir, un actor, y no necesita discutir ni dejar que otros lo hagan. Acción aquí significa 'fuerza' y 'violencia'.

El partido totalitario de Lenin fue, en efecto, un invento totalmente nuevo, y resultó ser el modelo para todos los partidos totalitarios posteriores, como por ejemplo los partidos comunistas de Europa y Asia, y los partidos nazis y fascistas de Europa, Oriente Medio e Hispanoamérica. Quiero hacer énfasis en el hecho que un partido sólo es completamente totalitario si también es fundamentalista. El marxismo-leninismo era una ideología fundamentalista como lo eran las ideologías del racismo. Y todas eran de carácter secular.

Si los partidos totalitarios toman el poder estatal, totalizan al estado. Si el estado ya está totalizado, empiezan a totalizar a la sociedad entera. Cuando digo «totalizar» me refiero a proscribir el pluralismo. El pluralismo, en una sociedad moderna, no se puede eliminar, pero se puede proscribir. Esto, de hecho, quiere decir que el partido determina qué opiniones son permitidas y cuáles prohibidas. Las opiniones prohibidas son por definición las del enemigo. El totalitarismo mantiene al partido, al estado y a la sociedad en un estado 
permanente de revolución; hace guerras interminables contra enemigos internos y/o externos. Los regímenes totalitarios necesitan una imagen muy fuerte del enemigo; tienen que satanizar al otro. Tanto el nosotros como el ellos se tienen que visualizar. El nosotros es representado por el póster del Führer, y el ellos, por cualquier enemigo político cuya efígie se pueda quemar. El «iLarga vida!» tiene que ir seguido por el "iAbajo!», como la famosa novela de Silone.

Sin embargo, no todas las organizaciones, estados o sociedades totalitarias son terroristas. Todos los grupos totalitarios se comportan de forma brutal con sus enemigos: planean asesinatos, asesinan a muchos y envían aún a más gente a campos de concentración. Pero terror quiere decir 'asesinato indiscriminado'. El terror reina si no hay la más mínima relación entre los actos y el comportamiento de una persona, de un lado, y el hecho que sea escogida como víctima del asesinato masivo, del otro. El terror es totalmente irracional desde la perspectiva de la víctima, la cual no puede evitar que ella o su familia sean asesinadas — ni con la lealtad más estricta al grupo terrorizador. Pero el terror es completamente racional desde el punto de vista del terrorista. La palabra terror tiene dos significados: 'miedo e intimidación sin precedentes', por un lado, y 'asesinato indiscriminado', por el otro. El objetivo del terror desde la perspectiva del terrorista es exactamente esta intimidación. Todo el mundo debe tener miedo. El miedo y la fe se pueden fusionar psicológicamente. Cuanta más gente te teme, más importante eres.

Se puede debatir si la Unión Soviética era un régimen del terror desde sus principios o si aconteció en vano en la época de la colectivización. En tiempos de Lenin, los miembros de las denominadas "clases enemigas" también eran un objetivo, además de los enemigos políticos reales, sospechosos o potenciales. De todos modos, con la colectivización (la totalización de la sociedad entera), el terror llegó a su punto álgido y, excepto durante los años de guerras, no disminuyó hasta la muerte de Stalin. Muy parecido es el caso de la Alemania nazi. Dado que los judíos — niños y no nacidos incluidos- eran seleccionados como objetivos enemigos sin provocación, se puede decir que el régimen era terrorista desde el principio. Se podría decir, no obstante, que se volvió terrorista a partir de 1939, cuando se ejecutó el plan para exterminar a los judíos y a otros colectivos.

Hago estos bocetos no para explicar Bin Laden y su organización terrorista, sino para ocuparme en una clase de genealogía. Aquello que ya ha sido inventado, que ya ha hecho sentir su presencia en el mundo (en este caso el terrorismo totalitario), se puede combinar fácilmente con elementos de paternidad diferente. Más adelante volveré a la discusión de los rasgos comunes entre los estados totalitarios europeos y la organización, ideología, miembros y acciones del grupo de Bin Laden. Primero, permitidme empezar por su genealogía.

Tras la Segunda Guerra Mundial, varios grupos pequeños de acción y terror aparecieron en escena, desde Europa hasta Japón pasando por Hispanoamérica. Eran relativamente independientes los unos de los otros, al menos al principio. Opino que no todas las organizaciones que en aquellos tiempos se deno- 
minaban «terroristas» lo eran. Para los supuestos asesinatos cometidos por grupos, el objetivo de los cuales son políticos concretos, por parte de agentes secretos o la policía, yo emplearía el término «asesinatos politicos», no «terroristas». Esto no quiere decir que apruebe la entonces extendida veneración de aquellos grupos como héroes, como los Tupamaros, por parte de ciertos intelectuales (ya argumenté en contra entonces). Tampoco abordaré aquí el terrorismo étnico-nacional, porque estos grupos tienen un objetivo concreto, a veces con cierta razón, a veces sin ella. Querría, más bien, concentrarme en el terrorismo alemán e italiano, en las Brigadas Rojas y su réplica fascista, por un lado, y en la Baader-Meinhof, por el otro, y además en las unidades terroristas de Oriente Medio en Líbano y en Siria, promovidas a la sazón por la Unión Soviética. Este último punto es importante, porque por eso es por lo que se les denominaba «izquierdistas». A los predecesores de Bin Laden se los denominaba «izquierdistas» porque tenían el apoyo de los soviéticos, mientras que a los que tenían el apoyo de los Estados Unidos se les denominaba «derechistas». De este absurdo flagrante se desprende, y se da por hecho, que los Estados Unidos ayudan a los «derechistas» como la democrática Israel, mientras que la Unión Soviética ayuda a los «izquierdistas» como los militantes musulmanes del Líbano. Esta ideología, aunque absurda, ha ayudado a preparar el primer intento de globalizar las redes del terror.

De hecho, la distinción entre izquierda y derecha, pese a la irracionalidad de su imputación, aún indica una relación existente con una tradición política. Claro está que las Brigadas Rojas no eran «izquierdistas» en sentido político, como tampoco los asesinos en masa del ferrocarril de Bolonia eran «derechistas» en un sentido político.

Como en todos los casos de genealogía, tengo que simplificar la historia. ¿Qué es lo que era nuevo aquí? ¿Qué novedad aportaban al mundo los terroristas de posguerra? Eran, o se convirtieron en, terroristas, entre otras razones porque inventaron el secuestro como medio de chantaje político. El secuestro utiliza civiles al azar como rehenes para conseguir objetivos políticos, como liberar camaradas encarcelados o difundir las ideologías del grupo. Incluso en estado de guerra, la toma de rehenes es un caso evidente de conducta injusta de guerra. Tomar civiles al azar como rehenes, y finalmente matarlos, se convirtió en una práctica general en tierra, y no solamente en el aire. Estos terroristas, especialmente en Europa, no tenían ninguna intención de apropiarse del estado; sus objetivos eran principalmente negativos: intimidación, subversión, desbaratamiento y, en general, dejar a cuerpo descubierto las debilidades del sistema democrático y del estado. Fueran o no anticapitalistas en su retórica, todos odiaban a la democracia existente, el estado, el liberalismo, el stablishment y la hipocresía. Porque tenían "aversión» a la forma de vida burguesa y a la prosa diaria, compartían la veneración por los héroes bolcheviques, fascistas y nazis, pero no tenían Führers. Incluso Baader, la carismática figura masculina de su grupo, no era un Führer. Pero este hecho mismo, junto con la ausencia de un diseño concreto para apropiarse del poder de cualquier estado, hizo que estos grupos terroristas constituyeran el empujón inicial del terrorismo global. 
Conectaron; planearon acciones conjuntas. Los terroristas alemanes se entrenaron en campos del Oriente Medio; como resultado, su ideología incluía una fuerte retórica antiisraelí y antisemita. Estos grupos terroristas nunca fueron vencidos del todo, sino que se fueron marchitando - primero, porque la oleada de la «nueva izquierda» que durante un tiempo aumentó sus actividades, a la larga les robó los simpatizantes políticos, y, segundo, porque el terrorismo «de derechas» y "de izquierdas» perdió su apoyo financiero y organizativo con la desaparición de la Unión Soviética.

Una observación más. Los grupos de terror relativamente pequeños se unieron sólo por ideologías fundamentalistas, no por cuestiones de raza, clase o religión. También eran extraterritoriales en el sentido de que en ninguna parte estaban en casa, y no tan sólo porque poco a poco acontecían globales. Es por esto que no practicaban la limpieza étnica tal y como lo hacían los regímenes totalitarios y de terror. La limpieza étnica como flagrante violación de los derechos humanos y civiles es una probable, pero no necesaria, manifestación del terror, y ha sido practicada por estados que no eran totalitarios, ni siquiera autocráticos. En el caso del terror global, Bin Laden y su organización obviamente quieren "limpiar» Oriente Medio de judíos y, puesto que esto parece imposible, podrían recurrir a la limpieza religiosa entre los musulmanes. Pero se trata de una mera especulación.

Para la aproximación genealógica, tenemos que hacer una catálogo preliminar de los elementos comunes entre todos los estados $u$ organizaciones terroristas. Estos elementos se combinan, pues, de diferentes maneras, se tumban boca abajo y se combinan con elementos nuevos o con elementos procedentes de diferentes orígenes. Permitidme ofrecer algunos ejemplos, repito, sólo a guisa ilustrativa. Al contrario que las ideologías fundamentalistas, paganas o ateas, de las organizaciones nazi y bolchevique, nuestro terror global contemporáneo utiliza la religión (una religión) como ideología. Esto no es mejor ni peor que las ideologías seculares del terror, si se me permite expresarme en estos términos tan poco adecuados, sin embargo, es obviamente diferente y, por lo tanto, se necesitan estrategias nuevas si es que lo tenemos que entender. Los destinatarios del terror global contemporáneo no son clases ni razas, sino musulmanes. O, para formularlo mejor, estos nuevos terroristas se presentan como gente del islam, tal y como los nazis se presentaban como gente de la misma raza que la gente a quien se dirigían, y los bolcheviques se presentaban como una clase mitológica denominada "proletariado». Como tales, los nuevos terroristas necesitan inventar un «relato impresionante». Y, de hecho, Bin Laden lo hizo en una entrevista en la televisión, durante la cual relató la historia de la frustración musulmana empezando por la ocupación de Jerusalén por parte de los cruzados, continuando por la Reconquista de España y llegando hasta la ocupación judía de Jerusalén. Otra combinación nueva es que el objetivo de los terroristas contemporáneos no es tomar el poder de un estado, sino infiltrarse ideológicamente en todos los estados musulmanes. Su objetivo es convertirse en los únicos agentes de poder de estos estados y, por lo tanto, dominar el mundo. Desde luego que los nazis y los bolcheviques compartían este último 
objetivo, pero primero necesitaban un poder estatal absoluto para poderlo llevar a término. Parece ser que un fundamentalismo de base religiosa no necesita un estado totalitario como centro absoluto para tramar la conquista del mundo. Parece una guerra de culturas pero no lo es. Tiene tan poco de guerra cultural como la guerra de los nazis tenía de guerra entre razas y el proyecto bolchevique, de guerra de clases.

¿Cuáles son los rasgos comunes de todos los tipos de terror moderno que hemos discutido antes? Claro está que no conocemos a ciencia cierta la identidad de los arquitectos del terrorismo suicida del 11-S, y quizás nunca la conoceremos. Del mismo modo, nunca nadie probó más allá de cualquier duda que los nazis prendieron fuego al Reichstag o que los soviéticos masacraron a los oficiales polacos en 1939. Como dice la canción de Beggar's Opera, de Brecht-Weil: «un tiburón no es un tiburón hasta que no lo puedas probar».

Pero el Führer de una organización totalitaria es aquél que aparece como Führer. Bin Laden es el Führer del terrorismo global contemporáneo, porque aparece como tal, porque se ha hecho con el papel. Bin Laden es el líder de una organización totalitaria y, por lo tanto, por definición, es el Führer. Como líder de su organización, Bin Laden es la fuente de todo el poder. Su mito es una realidad como lo eran los mitos de Hitler o Stalin. Sabemos por los libros de historia que, en tiempo de gran peligro, cuando la Unión Soviética fue atacada por Alemania, Stalin se asustó y se quedó en un estado de indecisión, completamente impotente, mientras otros tomaban las decisiones por él. Aún así, continuaron dándole el mérito de todas las decisiones, porque sin una fe absoluta en el Führer ningún mecanismo totalitario puede funcionar adecuadamente. Por eso es por lo que creo que tiene sentido concentrarse en la captura o eliminación de Bin Laden, y la razón por la que considero que el argumento contrario, que vendrá de otros que tomarán su lugar, es razonable pero poco sólido. Hasta que Bin Laden no reclamó la posición de Führer, mientras sus pósters y retratos no eran llevados en cada manifestación antiamericana, era fácilmente sustituible, pero esto ahora ya sería difícil.

Como ya hemos tratado, un partido totalitario - por prohibir el pluralismo- necesita una ideología fundamentalista o cerrada. Esta vez es el islam. El uso de las ideologías es similar en todas las ocasiones. En este caso, aquél que no acepte completamente la interpretación fundamentalista del islam, no es considerado en absoluto musulmán, sino un agente de los cruzados o de los judíos; es un enemigo. No me cansaré de repetir que el islam ejerce la función de ideología. Casi todas las religiones tienen un fundamento, y parece que se pueden movilizar fácilmente como creencias fundamentalistas. Aun así, el fanatismo religioso (la única fuente del mal moral en la narración de Descartes) hace normalmente una demostración de fuerza en tiempo de desbaratamiento de identidades y competencia religiosa. Pero este desbaratamiento de identidades y la competencia de explicaciones del mundo, ética, etc., ya no son excepcionales; son el estado del mundo moderno. Y el fanatismo y fundamentalismo es tan sólo una de las muchas respuestas religiosas a su desafío. Entre las otras, encontramos la fe religiosa interior, las comunidades religio- 
sas pequeñas y abiertas aún al diálogo, ecumene, y la tolerancia religiosa entre religiones tradicionales y nuevas.

En el caso del fanatismo religioso (y el uso ideológico de la religión en la política es por definición fanático), la condena moral del enemigo es fácil y, normalmente, se concentra en la sexualidad, especialmente en la de las mujeres. El fundamentalismo (religioso o no) moviliza todas las reservas del resentimiento, la agresión y el odio. Y el resentimiento se moviliza mejor cuando es el objetivo, la riqueza y/o la libertad sexual, es decir, cuando los deseos inconscientes se pueden canalizar en una enemistad intensificada.

Una organización totalitaria es, como ya sabemos, centralizada y jerárquica; funciona como un ejército por la vía de relaciones de mando y obediencia, y, por lo tanto, se ajusta perfectamente a la operación clandestina y al ejercicio del terror. Una organización parecida, como Al Qaeda, se muestra como un poder homogéneo. El poder homogéneo es atractivo, y si — como es ahora nuestro caso- - se institucionaliza, es una institución carismática. Un poder inflexible, autosatisfecho e hipócrita, si está bien movilizado y organizado para la acción, es sobre todo carismático, como lo son también sus Führers. Según ellos, toda disensión es una traición. Y dado que el carisma se extiende ampliamente entre los grupos de apoyo, en este caso entre los musulmanes, la disensión o las diferencias de opinión se considerarán una traición, e incluso los librepensadores serán considerados unos traidores. Siempre que veo por televisión la cobertura de una manifestación de entusiastas de Bin Laden y los veo quemando banderas de los Estados Unidos y la efígie del presidente de los Estados Unidos, recuerdo manifestaciones y griteríos parecidos en Budapest, a principios de los años cincuenta, cuando se prendía fuego a las efigies del presidente Truman y todo el mundo gritaba al unísono: "América nos destruiría si tuviera la posibilidad». Allí aprendí también que el miedo y la fe se refuerzan mutuamente la una a la otra, y que siempre que el miedo ha marchado, le sigue inmediatamente la fe (excepto los creyentes genuinos, quienes siempre son, no obstante, la minoría en estas manifestaciones). No quiero despreciar el peligro del fanatismo de masas, sino hacer énfasis en que siempre está del lado de los aparentes ganadores, no de los perdedores. Bin Laden debe su adoración actual como héroe al ataque terrorista contra los Estados Unidos (lo haya organizado o no), y de aquí se deduce que tiene que continuar esta acción. Si Bin Laden quiere conservar su popularidad, ha de añadir otras victorias a la del $11-\mathrm{S}$. Si no puede, perderá el apoyo y muchos de sus seguidores perderán la fe. De aquí el anhelo de hacer una revolución permanente.

Ya he mencionado que a los regímenes y las organizaciones del terror les hace falta una imagen fuerte o un mito del enemigo. Se tiene que presentar al enemigo como un compendio de todos los males, incluso de los «males» que se contradicen, como el comunismo y el capitalismo. El mejor ejemplo conocido es la palabra insultante de Hitler: «judeo/plutócrata/bolchevique». La expresión en efecto describe enemigos mitológicos. Los judíos eran el enemigo número uno del nazismo. De hecho, la guerra de los nazis se hizo primeramente contra los judíos. Pero, en otras organizaciones y estados totalitarios 
y del terror, los judíos (hasta Bin Laden) no estaban entre los principales enemigos. El "capitalismo», el «imperialismo» y los ajenos a las clases en general, eran el enemigo número uno para el régimen soviético. Aparentemente, aquí tratamos con el enemigo común de todos los grupos y estados terroristas. Acabo de mencionar la retórica antiplutocrática de Hitler. La mayor parte de los grupos terroristas europeos y japoneses eran «antiimperialistas», y el capitalismo global es visto como uno de los más grandes enemigos del terror global. Pero los cerebros que hay detrás el terror global son también capitalistas globales, del mismo modo que Hitler tenía el apoyo de los industriales y los financieros alemanes (repito que dejo fuera el fascismo italiano, porque no era un régimen del terror tal y como yo entiendo la palabra terror, aunque se volviera totalitario en la República de Salo, tratara cruelmente a los enemigos y presuntos enemigos, y practicara la limpieza étnica). Así, el capitalismo servía a menudo como eslogan, y se usaba principalmente para conseguir el resentimiento masivo contra los ricos en apoyo de la guerra racial, religiosa y territorial.

Quizás sea irónico que los terroristas globales puedan airear discursos de odio contra la tecnología y los medios de comunicación modernos mientras utilizan tecnologías y medios de comunicación modernos. La red del terror opera de maneras diez mil veces más sofisticadas que el Comintern de Stalin. Los nuevos terroristas se comunican vía correo electrónico, por Internet y a través de teléfonos móviles. Pero la ironía es, después de todo, un signo de «decadencia» y ruina moral. El uso de redes de comunicación globales hace que el terrorismo global sea más invisible y más ilocalizable que sus predecesores. Otro tipo de ironía es que, aunque los cerebros que hay detrás el terrorismo desprecien el racionalismo del mundo secular, ellos traman sus planes con la máxima racionalidad. No es la ira de Dios que invocan; al contrario, calculan cada paso de antemano, y traen registros precisos de todos los medios necesarios para conseguir sus objetivos, por ejemplo: la cantidad de combustible que trae un avión con un destino determinado.

La retórica antiburguesa del terrorismo global parece incluso más falsa si damos una breve ojeada al historial familiar y educativo de los denominados «actores» - a la información biográfica sobre los terroristas suicidas reales y potenciales y otros activistas "profesionales». Ya he mencionado antes que todos los miembros confirmados de grupos terroristas, los detenidos o arrestados en Europa y los que están bajo investigación, son musulmanes, principalmente la estirpe de las clases medias acomodadas. Lo más importante es, no obstante, que tienen educación universitaria. Son intelectuales frustrados. La primera generación de líderes comunistas soviéticos también consistía principalmente en intelectuales frustrados. Uliánov (conocido como Lenin) no pudo continuar su carrera académica debido a la participación de su hermano en el atentado contra la vida del zar y a su posterior ejecución. Dzhugashvili (conocido como Stalin), autor de poemas modernistas, saltó al comunismo desde un seminario ortodoxo. Y tendremos que recordar que Goebbels siempre firmaba sus discursos propagandísticos como Dr. Goebbels. Jóvenes que quieren parecer extraordinarios en un mundo muy ordinario, que tienen grandes 
ambiciones sin tener gran talento, o que se enfrentan a verdaderas dificultades externas en la consecución de sus carreras, se dejan llevar fácilmente por credos y mitos de heroísmo. Algunos se pararán en un punto del continuum que otros seguirán hasta el extremo. Estos jóvenes persiguen el espectro de la immortalidad, ya sea una fama inmortal o un lugar en el paraíso. Los primeros quieren ser recordados eternamente por la historia; los segundos quieren entrar inmediatamente en el paraíso. Si realmente llegan a asesinar o no, no me parece tan distinto.

Las universidades masivas son fábricas para la producción de intelectuales frustrados y seguirán siendo campos de entrenamiento para todo tipo de extremismos. Qué tipo de extremismos tendrá lugar en el futuro nadie lo puede decir aún. El extremismo virulento lo hemos de abordar ahora. Pero, entonces, ¿cuál es el enemigo común?, ¿quién es el enemigo? Porque hay, ciertamente, un enemigo común, a quien odian y contra quien luchan todas las organizaciones totalitarias, los estados del terror y las redes del terror. Este enemigo común no es el capitalismo, ni la tecnología moderna. Es la democracia liberal, los derechos humanos y el secularismo. Por «secularismo» no quiero decir la muerte de las religiones. Después de todo, el enemigo más odiado, Estados Unidos, al contrario que la mayor parte de estados europeos, es un país absolutamente religioso. Por secularismo, me refiero a la posibilidad de escoger entre religiones o de no escoger ninguna; la división de las esferas de la religión, estética, política y económica, y, finalmente, la posibilidad de escoger entre una gran variedad de formas de vida. La libertad es el enemigo común.

La modernidad se basa en la libertad, con todo lo que ello comporta; la libertad es un fundamento que no funda. En libertad se puede optar en contra de la libertad, se puede escoger libremente la no-libertad. Ésta es la opción de los fundamentalistas. No renuncian a la modernidad; no renuncian al capitalismo o a la tecnología moderna; no renuncian al racionalismo o a la ilustración en general. Pero sí renuncian a una interpretación de la ilustración, es decir a la de Kant. La ilustración, dice Kant, es la salida del ser humano de su minoría de edad, de la cual él mismo es culpable (en la modernidad, el ser humano siempre es culpable de la minoría de edad). El fundamentalismo, o la pertenencia a una organización totalitaria, es un retorno a la tutela. Significa renunciar a las tres máximas del entendimiento humano ilustrado: piensa con tu cabeza (pensamiento independiente), piensa en el lugar del otro (pensamiento ampliado) y piensa consecuentemente. El fundamentalismo renuncia al pensamiento independiente, rehúsa el pensamiento ampliado y —en sus ejercicios de propaganda- pretende reírse del pensamiento consecuente.

Las tres máximas del entendimiento humano son máximas o normas. Poca gente las sigue completamente. Las cargas del pensamiento independiente son las cargas de la libertad, y son arduas. Todos nosotros tenemos prejuicios, y por eso es por lo que nos es difícil pensar en el lugar de otro. Por otra parte, pensar consecuentemente es, a lo mejor, la máxima más difícil de seguir, puesto que siempre que nuestros valores o preferencias estén en juego, creeremos que somos consecuentes, y necesitaremos de otros para que nos digan que no lo 
somos. Es muy difícil navegar entre el fundamentalismo y el nihilismo, entre el fanatismo y el cinismo, y entre unas visiones del mundo totalmente cerradas y el relativismo total. Y es exactamente esta difícil navegación la que se tiene que defender. ¿Por qué nosotros - los demócratas, liberales - tenemos que pedir perdón por estar totalmente convencidos de que la posibilidad abierta por esta navegación es el tesoro del laberinto de la vida moderna? ¿Por qué a menudo nos da vergüenza decir sencillamente «no!», sin florituras, siempre que este tesoro se convierte en un objetivo para el odio, siempre que los autoproclamados redentores intentan destruirlo?

Como respuesta al reto del terror global, repito las palabras de otro hombre de la ilustración. Afrontando un acto de asesinato motivado por el fanatismo religioso, Voltaire se dirigió a sus compatriotas con esta orden: «Ecrasez l’infame!» («iAplastad al infame!»). Yo añadiría: «y puedes estar seguro de que después vendrán otros». 